\title{
El estado de excepción a comienzos del siglo XX: de la cuestión obrera a la cuestión nacional
}

\section{State of exception at the beginning of the twentieth century: from the working-class question to the national question}

\author{
Marina Franco \\ Universidad Nacional de San Martín \\ Consejo Nacional de Investigaciones Científicas y Técnicas \\ marfrancomail@gmail.com
}

(Argentina)

\section{Resumen}

Este artículo analiza las medidas de excepción tomadas durante la primera década del siglo XX como mecanismo de disciplinamiento social y resolución de los conflictos obreros durante esos años. Para ello se analizan las leyes de excepción permanentes ("Ley de Residencia" y de "Defensa Social") así como las medidas de estado de sitio que fueron recurrentes entre 1902 y 1910. Esta legislación afectó diversas categorías definidas por la propia legislación como inmigrantes y extranjeros "perturbadores" de la seguridad nacional y "anarquistas y demás personas" consideradas "peligrosas". El objetivo del trabajo es abordar el conjunto de esta normativa como legislación de excepción y observar algunos mecanismos específicos puestos en marcha para responder a la cuestión social y obrera en esos años. Este trabajo se inserta en una línea de investigación más amplia sobre las formas y prácticas represivas del Estado y sus diferentes agencias y actores a lo largo del siglo XX.

Palabras Clave: estado de excepción, represión, Ley de Residencia, cuestión social, Argentina. 


\begin{abstract}
This article analyzes the exceptional measures as mechanisms of social discipline and labor conflict resolution enforced during the first decade of the $20^{\text {th }}$ century. It examines the laws of permanent exception, i.e. the "Law of residency" and "Social defense law," as well as the recurring state of siege between 1902 and 1910. These laws affected those segments of the population defined as "agitators" of national security, while "anarchists and other individuals" were regarded as "dangerous". The article examines this legislation as part of a whole body of exceptional measures and it also allows a closer look at certain specific mechanisms activated to respond to social and working-class issues. This work forms part of a broader-scope research on the state's repressive modes and practices as well as its diverse agencies and players throughout the $20^{\text {th }}$ century.
\end{abstract}

Keywords: state of exception, repression, law of residency, social issues, Argentine.

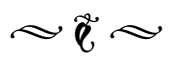

\section{Introducción}

Este trabajo ${ }^{1}$ analiza una serie de medidas legislativas y del poder ejecutivo argentino tomadas en la primera década del siglo XX que, en su conjunto, configuraron una situación de excepción jurídica sostenida y focalizada sobre los conflictos obreros, y sociales por extensión. Esa situación se construyó en la articulación entre leyes permanentes de restricción de derechos y una serie de medidas de emergencia coyuntural -es decir, leyes y decretos de estado de sitio- de duración más breve pero de uso recurrente y sistemático durante la primera década del siglo. Las medidas del primer tipo que se analizarán aquí son la "Ley de Residencia" de 1902 y la "Ley de Defensa Social” de 1910 $y$, entre ambas, la aplicación regular del estado de sitio en 1902, 1905 (dos veces), 1909 y

1. Agradezco la generosidad de Martín Albornoz para discutir conmigo este trabajo así como los comentarios de los integrantes del Núcleo de Historia Reciente del Instituto de Altos Estudios Sociales de la Universidad Nacional de San Martín.
1910. Esta legislación puede ser tomada como conjunto en razón de que estuvo orientada a resolver por la vía de la restricción de derechos y la configuración de una situación de excepción jurídica lo que para la época se dibujaba ampliamente como "la cuestión obrera" y "social". Sin embargo, en buena parte de la argumentación de la época -y en algunas miradas historiográficas- ese problema aparece restringido a la "cuestión anarquista" o, a lo sumo, el problema de los extranjeros "indeseables".

El argumento de este trabajo es que el estado de excepción fue el mecanismo de disciplinamiento regular que la élite utilizó para enfrentar la cuestión obrera en ese periodo cada vez que se sintió amenazada por situaciones de conflicto laboral generalizado y de alta tensión social. Esta política fue sistemática a lo largo de la década en el mismo momento en que, como consecuencia de esa conflictividad, empezaban a surgir una serie de debates y políticas específicas tendientes a introducir reformas sociales así como a explorar otras formas de resolución 
de conflictos en el ámbito laboral. ${ }^{2}$ En la medida en que, a pesar de los sucesivos intentos de derogación, las dos principales leyes de excepción permanentes estuvieron vigentes largo tiempo -la "Ley de Residencia" hasta 1958 y la de "defensa social" hasta 1921-, la excepcionalidad jurídica siguió siendo la garantía última del control social cuando la situación se percibía amenazante. Como ha señalado Juan $\mathrm{Su}-$ riano (1989-1990 y 2000) desde fines del siglo XIX y especialmente en los años aquí analizados, el Estado comenzó a intervenir como árbitro de las relaciones sociales, articulando políticas consensuales para apaciguar el conflicto de clases y políticas represivas focalizadas en los agentes considerados perturbadores, es decir, la inmigración y el anarquismo. Este trabajo muestra que, durante la primera década del siglo, todavía se apeló insistentemente a las segundas, bajo la forma de la excepcionalidad jurídica, en los momentos de alta o muy generalizada conflictividad. Esto deja en evidencia la persistencia de las tendencias disciplinadoras a pesar de su convivencia con otras políticas de integración de los trabajadores. ${ }^{3}$

El dato clave que nos interesa explorar es que esa política disciplinadora se expresó en normativa de excepción. Nuestra pregunta nodal es entonces, ¿Qué puede aportar a la comprensión histórica el análisis de estas medidas como

2. En este punto coincidimos con la lectura historiográfica que sitúa los avances en las políticas de reforma social como reacción al crecimiento de la cuestión obrera y social. Véase: Oved (1976) y Suriano (1989-1990).

3. Entre las iniciativas reformistas gubernamentales y parlamentarias deben mencionarse, entre muchas, el proyecto de Ley Nacional de Trabajo de J. V. González en 1904, la aprobación de la ley de descanso dominical para la Capital Federal en 1905 y la creación del Departamento Nacional de Trabajo en 1907. Sobre esta tendencia reformista véase Zimmermann (1995). políticas de excepción? ¿Qué nos permite entender el estudio de las políticas represivas bajo esta óptica? ${ }^{4}$ Sin duda, el recurso sistemático a ese tipo de medidas es un indicador del temor y del sentimiento de amenaza que envolvía a las élites políticas argentinas a comienzos del siglo XX en momentos de conflicto y protesta obrera generalizados. Ese proceso fue más profundo que las siempre evocadas leyes de "Residencia" y de "Defensa Social" pues el uso del estado de sitio muestra la reiteración sistemática de la decisión de enfrentar los conflictos laborales grandes, o que afectaban intereses nodales, por la vía de la excepcionalidad. Que la gestión del conflicto se resolviera por esa vía que implica la suspensión temporaria pero recurrente de derechos constitucionales, y/o su suspensión permanente para ciertos sectores sociales, expresa toda una concepción del orden social y de quienes pertenecían a él o no. Desde luego que el uso efectivo de las leyes permanentes de excepción fue fluctuante -especialmente en lo que concierne a la "Ley de Residencia” en la primera década- pero su vigencia legal como instrumento disponible expresa las concepciones que nos interesa observar. No es lo mismo que la resolución de los conflictos se realice por la vía directamente represiva o que ésta esté mediada por figuras legales -que suspenden la legalidad-, de la misma manera que no son iguales los efectos de legitimidad de la autoridad estatal que surge de ello. Desde un punto de vista analítico, la

4. Entiendo por mecanismos represivos aquellos instrumentos de gobierno para el control y sanción a través del empleo de la coerción, o la amenaza de usarla, dirigidos contra individuos o grupos que se consideran desafíos a las relaciones de poder existentes o a las políticas de gobierno. Estos instrumentos incluyen desde las estrategias reactivas (represión) hasta las preventivas (inteligencia y legislación restrictiva) para amedrentar posibles desafíos al orden. Para una discusión sobre estos elementos, véase González Calleja (2006). 
exploración de las estrategias simbólicas utilizadas, los recursos políticos movilizados y las maneras en que esas medidas se legitimaron permite entender mejor las percepciones sobre el orden social y sus conflictos, las implicancias profundas del uso de ese tipo de normativa y sus consecuencias políticas y sociales. ${ }^{5}$

Por otro lado, si bien el foco de este trabajo está puesto en los dispositivos legales y por tanto en el poder ejecutivo y legislativo, es importante considerar que la aplicación de las políticas de excepción en la primera década del siglo se sostuvo, fundamentalmente, a través de la intervención policial y ello marca una diferencia importante en relación con otras modalidades posteriores. Así como en largos periodos de la historia argentina, especialmente la segunda parte del siglo XX, el recurso sistemático a la excepción descansó sobre la articulación de gobiernos civiles con fuerzas armadas, en esta primera década, la articulación más estrecha se construyó con una agencia policial en formación. Desde luego las tropas militares fueron usadas reiteradamente también, pero no fue la fuerza central con la que se estructuró la acción represiva urbana. En efecto, la aplicación del estado de sitio y de leyes de excepción estuvo respaldada por cambios en la estructura, recursos, técnicas y despliegue policiales en torno a la persecución de los sectores trabajadores, muy especialmente del anarquismo. Ello fue así en particular durante la jefatura de Ramón L. Falcón, pero también bajo el mando de Francisco Beazley y la creación de la Sección de Orden Social, especialmente dedicada a la

5. Desde luego se podría mirar el argumento desde un ángulo distinto y sostener que el problema no era tanto el sentimiento de amenaza sino que el estado de excepción era el mecanismo regulatorio habitual de la conflictividad social y política en la Argentina de orden oligárquico. Volveremos sobre esta cuestión en las conclusiones. persecución de anarquistas y socialistas y a la expulsión de extranjeros, así como a través del uso de diversos avances científico-técnicos al servicio de las tareas de control policial (Barry, 2009; Périès, 2013).

En función de este enfoque, a continuación abordaré la mencionada legislación como un conjunto, aunque respetando sus marcas temporales específicas y los cambios internos a ese conjunto. Trabajaré a partir de los textos legales, las intervenciones y debates parlamentarios que le dieron origen, así como las coberturas e intervenciones periodísticas y jurídicas que se generaron desde distintos sectores de la élite y de los grupos afectados. El corpus periodístico abordado corresponde a los diarios La Prensa, La Nación (LN), La Tribuna (LT), La Vanguardia (LV), La Protesta Humana/La Protesta (LPH y LP) y la Revista del Arzobispado de Buenos Aires (REABA). ${ }^{6}$ Por último, es importante aclarar que este trabajo forma parte de una mirada de largo plazo sobre la legislación de excepción en la Argentina y las políticas represivas implementadas a lo largo del siglo XX con el fin de entender en qué momentos, con qué instrumentos y dispositivos simbólicos y materiales y sobre qué sujetos las agencias y actores estatales desplegaron su fuerza disciplinadora.

6. El relevamiento estuvo sujeto a la disponibilidad de la prensa en hemerotecas de Buenos Aires, que no siempre cuentan con series completas legibles. Por otro lado, un dato fundamental es que La Vanguardia y La Protesta Humana/La Protesta permanecieron cerradas durante largos periodos como consecuencia de las leyes de estado de sitio y los periódicos comerciales estuvieron bajo la prohibición de informar sobre los conflictos obreros durante la vigencia de esas medidas. Agradezco a Lady Heidenreich su generosidad para facilitarme el acceso a algunas de estas fuentes. 


\section{Estado de excepción y medidas de emergencia como instrumento de análisis}

Los estados de derecho modernos incorporan en su interior medidas particulares de emergencia o excepción (estado de sitio, ley marcial, decretos de urgencia, etc.), que se basan en un mismo concepto: la suspensión total o parcial del orden jurídico en nombre de su preservación cuando se considera que ese orden o el Estado están amenazados. En estas situaciones, como ha mostrado Giorgio Agamben, el Estado de derecho es suspendido desde adentro del ordenamiento jurídico. Así, la paradoja que se plantea es que para garantizar su supervivencia el Estado de derecho se suspende a sí mismo, creando una situación de indeterminación jurídica (Agamben, 2007).

El segundo elemento que interesa destacar es que en las situaciones de emergencia o excepción la amenaza al orden instituido es presentada como una realidad objetiva; quien decide que un acontecimiento particular configura una situación de necesidad es quien tiene la potestad de definir que es necesario recurrir al estado de excepción y definir las medidas a tomar (Agamben, 2007; Schmitt, 1985). En la práctica, las medidas de excepción son un instrumento que permite administrar el conflicto político amparándose en la legalidad de suspender la legalidad. Por ello, permite reducir a adversarios concretos como a cualquier $\mathrm{ca}^{-}$ tegoría social que se considere no integrable $u$ opuesta a los modos de vida consagrados por el poder instituido. En estas situaciones el poder hace uso de una violencia que puede ser liberada gracias al espacio de indeterminación que se genera entre el adentro y el afuera del derecho y la ocultación de los sentidos políticos de esa decisión. Además, dado que es el poder el que define los grupos enemigos, los contornos de esa definición y las medidas a aplicar, los instrumentos de excepción liberan posibilidades difícilmente controlables de antemano (Agamben, 2007).

En esos actos, los gobiernos colocan en el lugar de lo ilegal a quienes son indicados como causantes de la supuesta necesidad de autodefensa del Estado. Desde este punto de vista, y como resultado de la evidencia empírica de otros periodos de la historia argentina analizados por diversos autores ${ }^{7}$, consideramos que la instalación de situaciones de excepción es indisociable de la construcción de enemigos internos en tanto es lo que permite justificar la existencia de la situación de necesidad que habilita la excepción.

Como veremos en los casos analizados, las medidas de la década implicaron suspensiones temporales de las garantías constitucionales -esto es, del Estado de derecho- junto con suspensiones de tipo permanente para ciertos grupos políticos y demográficos. Así, se puede hablar de un verdadero estado de excepción como amenaza siempre vigente -aunque no permanentemente aplicada- sobre ciertos sectores sociales: inmigrantes y trabajadores, todos ellos pertenecientes a los estratos más pobres de la sociedad. ${ }^{8}$ Desde luego, las expe-

7. En particular, durante los periodos constitucionales de Frondizi y el tercer gobierno peronista, la construcción de enemigos en torno al comunismo, el peronismo y la subversión sostuvieron la puesta en marcha de políticas de excepción profundamente represivas (Franco, 2012a y 2012b). Para el gobierno de Frondizi específicamente, véase Marengo (2018) y Pontoriero (2016).

8. Desde nuestra óptica, es importante distinguir medidas de emergencia o excepción (por ejemplo el estado de sitio) que pueden ser puntuales o de alcance acotado, de los estados de excepción, en tanto estos últimos son el resultado de medidas sostenidas y acumuladas. 
riencias y estrategias de estos grupos y actores frente a las decisiones gubernamentales o las enormes fisuras de ese orden son cuestiones centrales, pero aquí nos interesa abordar el problema desde la lógica de la autoridad estatal (ejecutiva y legislativa) y la construcción de su legitimidad simbólica.

En efecto, el último elemento que interesa destacar, a partir del análisis de diversos casos empíricos, es la productividad simbólica -para diversos actores y espacios estatales- de definir una situación como de excepción. Como acto oficial, público y con pretensiones de universalidad (Bourdieu, 2014), con ello se definen sentidos y legitimidades desde y en nombre del Estado. Esto permite pensar el recurso a la excepción, en términos de performatividad de la autoridad estatal, pues se construye un lugar de enunciación que se legitima en esa autoridad a la vez que se la refuerza (Taussig, 1995). Esto es particularmente importante en un momento en que esa autoridad está en proceso de construcción y afirmación.

\section{Las medidas de excepción de la primera década del siglo $X X$}

La legislación permanente de la década como parte de la "cuestión social" ha sido un tema recurrente de la historiografía sobre el periodo, así como de los trabajos de Historia Social sobre el anarquismo o el mundo obrero, en general, con énfasis en la "Ley de Residencia".

Esta distinción permite no sustancializar el estado de excepción y diferenciar situaciones que pueden ser muy diversas (en este punto, nuestra posición se distingue abiertamente de lo sostenido por Giorgio Agamben).

9. Sobre la "Ley de Residencia" entre otros, véase Albornoz (2017); Albornoz y Galeano (2017);
Como conjunto, las medidas han sido consideradas en algunas producciones académicas como los trabajos de Viviana Barry (2009), Juan Suriano (1989-1990 y 2000) y Eduardo Zimmermann (1995), que se detienen sobre ellas desde distintos ángulos. Barry observa las lógicas y prácticas policiales que se crearon en torno a la persecución del anarquismo y la implementación de algunas de esas medidas. Por su parte, Zimmermann analiza las dos leyes permanentes como medidas contra el anarquismo y discute el peso explicativo que la historiografía ha puesto centralmente en la reacción defensiva de las élites. En contraste, prefiere valorizar el clima de ideas de la época, los aspectos materiales (la debilidad de los recursos represivos policiales) y los hechos que motivaron la aplicación de estas leyes. Suriano en sus trabajos más recientes sobre la cuestión (2000) las considera parte de una "visión negadora del conflicto social como elemento inherente" de las sociedades capitalistas modernas (p. 118), en articulación tensa con el inicio de políticas reguladoras por parte del Estado. En contraste, las medidas de excepción temporales $\mathrm{y}$ como conjunto han recibido poco atención focalizada de la historiografía, a pesar de haber sido aplicadas sistemáticamente durante la década. No es la intención de este trabajo redundar sobre los enfoques existentes, sino aportar una lectura desde la Historia Política y desde el análisis de las lógicas estatales para entender las maneras cambiantes en que ciertos actores dieron forma a políticas de control social a lo largo del siglo XX y desde la autolegitimación de la autoridad estatal. ${ }^{10}$

Anzoategui, (1939); Aspell (1979); Domenech (2015); Giorlandini (1986); Larocca (2008); Nazar (2008); Oved (1976); Sánchez Viamonte (1956).

10. Dado que el foco está puesto en las lógicas estatales, esta perspectiva no indaga los usos sociales de esta 
Veamos las medidas más específicamente. Entre 1902 y 1910, se aplicó reiteradamente el estado de sitio y en casi todos los casos fue la respuesta gubernamental ante situaciones de huelga que afectaron los engranajes claves de la actividad agroexportadora. Con pocas excepciones, las medidas fueron solicitadas por el poder ejecutivo al Congreso, que las sancionó con amplísimo apoyo de ambas cámaras. En 1902 el conflicto comenzó con una huelga de estibadores que solicitaban un aumento salarial, la reducción de las cargas y de la jornada laboral. A ello se sumaron otros conflictos en varios puertos y en el Mercado central de frutas y verduras. El gobierno respondió enviando tropas y obreros para reemplazar a los huelguistas; frente a ello, el paro en solidaridad con los sectores afectados se extendió a distintos gremios. La alarma se hizo generalizada cuando la Federación Obrera Argentina, anarquista, declaró el 9 de octubre la huelga general y comenzó a paralizarse la actividad económica en el momento crítico de la exportación agropecuaria. En ese contexto el Congreso sancionó la "Ley de Residencia" y dos días después, como complemento y a instancias del ejecutivo, le agregó el estado de sitio por casi 40 días en la ciudad y provincia de Buenos Aires y de Santa Fe. ${ }^{11}$ En octubre de 1905 fueron los obreros estibadores de Rosario quienes comenzaron la huelga; la progresiva paralización del puerto y su extensión a otros gremios y zonas portuarias alarmó al gobierno, que propuso el estado de sitio al Congreso por 90 días y en todo el te-

legislación ni las formas en las cuales los actores afectados por ella generaron estrategias y aprovecharon sus consecuencias. Ver Albornoz (2017); Domenech (2015) y Suriano (2001).

11. Ley 4145, 26 de noviembre de 1902. Boletin Oficial de la República Argentina (BORA). Recuperado de: http:// www.infoleg.gob.ar rritorio nacional. ${ }^{12}$ En mayo de 1910, el estado de sitio se declaró en forma preventiva, ante las amenazas de huelga revolucionaria proclamadas por los anarquistas en los días previos a los festejos del Centenario, exigiendo -entre otras cosas- la derogación de la "Ley de Residencia" y la liberación de los presos por cuestiones sociales. ${ }^{13}$ La prensa de la época, imbuida de la celebración de las glorias del Centenario y bajo los fantasmas del anarquismo como gran amenaza al orden social, agitó, por ejemplo, la idea de que los anarquistas habían amenazado de muerte a los niños que cantaran el himno nacional el 25 de Mayo y les habían arrancado las escarapelas patrias. ${ }^{14} \mathrm{El}$ propio debate parlamentario se hizo eco de esas afirmaciones fundamentando en ello la gravedad de la amenaza ácrata. ${ }^{15} \mathrm{El}$ estado de sitio fue declarado el 14 de mayo y estuvo vigente por 4 meses y 18 días. Poco después le fue agregada otra ley de excepción permanente, la "Ley de Defensa Social". En esta ocasión, la ferocidad con que se ejerció la represión habilitada por el estado de sitio, y el apoyo social que encontró en diversos sectores políticos -incluso de la oposición- $\mathrm{y}$ en grupos de jóvenes porteños, implicaron un profundísimo golpe para el anarquismo (Suriano, 2001).

El estado de sitio de 1909 tuvo un proceso más complejo, ya que fue declarado por decreto (a

12. Ley 4924,10 de octubre de 1905. BORA.

13. Ley 7025,14 de mayo de 1910. BORA.

14. (junio de 1910, p. 494). Revista del Arzobispado de Buenos Aires (REABA). Biblioteca Nacional, Buenos Aires. Según esta publicación fue justamente la reacción a las amenazas anarquistas las que dieron impulso patriótico y popular a los festejos de mayo.

15. Cámara de Diputados. Diario de Sesiones (CDDS), 14 mayo de 1910 y Cámara de Senadores. Diario de Sesiones (CSDS), 13 mayo de 1910. Biblioteca del Congreso de la Nación (BCN), Buenos Aires. 
diferencia de todos los anteriores votados por el Congreso) luego del atentado en el que fuera asesinado el jefe de policía, Ramón L. Falcón, y su secretario, Juan Alberto Lartigau, en noviembre de ese año. El hecho estuvo precedido por varios atentados de bomba atribuidos al anarquismo y que generaron amplia alarma entre las élites. A pesar de tener detonantes $\mathrm{y}$ formas particulares, por sus motivaciones $\mathrm{y}$ objetivos $_{2}$ el estado de sitio de 1909 se inscribe en la misma serie que los procedentes. En realidad, el conflicto se había iniciado meses antes del atentado. Durante la manifestación del $1^{\circ}$ de mayo en Buenos Aires, que convocaba regularmente a los sectores trabajadores, la Policía y su Guardia de Seguridad desataron una feroz represión en la plaza Lorea. En respuesta, la Federación Obrera Regional Argentina (FORA) convocó a la huelga general; aquella "semana roja" paralizó prácticamente la ciudad, y dio lugar a nuevos ataques y persecuciones policiales con apoyo del Ejército (Barry, 2009; Frydenberg y Rufo, 1992). En esa coyuntura, a pesar de la crítica situación no se declaró el estado de sitio y solo se recurrió a él meses después, en un contexto donde la peligrosidad de la amenaza anarquista no parecería requerir justificaciones.

Para una adecuada apreciación de las prácticas políticas en torno a las medidas de excepción es importante considerar que en esa misma década hubo otras dos aplicaciones del estado de sitio que no fueron respuestas directas a la conflictividad obrera. La primera, en 1901, ante las protestas producidas por el anuncio gubernamental de la "unificación" de la deuda nacional. La medida no obedeció a conflictos laborales pero sí a movilizaciones sociales que se controlaron con la suspensión de garantías constitucionales (Rojkind, 2006). La segunda fue en febrero de 1905; esa vez el estado de sitio se sancionó por decreto en respuesta al intento de revuelta armada de la Unión Cívica Radical en varios lugares del país. Sin embargo, la medida se tomó en un contexto de fuertes movimientos huelguísticos de diversos gremios -especialmente del transporte ferroviario- y en medio de las noticias sobre los levantamientos revolucionarios en Rusia que tenían muy alarmada a la prensa argentina. ${ }^{16}$ Lo cierto, es que como consecuencia de la medida contra la revuelta radical fueron detenidos cientos de obreros y levantadas las huelgas, fueron clausurados locales sindicales, prohibidas las reuniones y allanados los diarios socialista y anarquista y, en el mes de mayo, fue reprimida una concentración obrera convocada por el Partido Socialista y la FORA. ${ }^{17}$ Así, por esta vía indirecta, el estado de sitio de febrero de 1905 también integra la serie analítica general con características similares.

La revisión somera de estas medidas reconfirma un uso regular del estado de sitio para esta década y su uso mayoritario para fines de control del conflicto obrero. ${ }^{18}$ Este uso del es-

16. Véase $L N$ y La Prensa desde fines de enero de 1905 sobre las noticias rusas. Antes del estado de sitio, $L a$ Vanguardia denunció, a comienzos de febrero, que el gobierno enfrentaba la huelga de ferrocarriles deteniendo obreros y enviando tropas militares a las estaciones para obligar a los empleados ferroviarios a trabajar. (4 de febrero de 1905). La Vanguardia ( $L V$ ). Archivo Personal de la Autora (APA).

17. (11 de febrero de 1905). $L V ;$ (23 de febrero de 1905). $L V ;(27$ de mayo de 1905). $L V ; 10$ de mayo de 1905. $(L V)$. En especial, denuncian intensamente la persecución política sistemática contra los obreros y la represión durante la manifestación de mayo que causó dos muertos y muchos heridos. En palabras del diario socialista:

"en medio de las alarmas que le produce el atentado [radical, quienes gobiernan] no olvidan su misión de clase dominante" (11 de febrero de 1905). $L V$.

18. Esto no significa que todos los conflictos sociales o huelgas generales fueron resueltas con estado de sitio. 
tado de sitio se torna un dato significativo si se considera que en la década anterior a 1902 no se utilizó para resolver conflictos socio-laborales, sino políticos en sentido estricto (en general vinculados a la relación con radicalismo) y luego no volvió a ser utilizado hasta 1930, aunque la conflictividad obrera fuera intensa e intensamente reprimida por los gobiernos radicales en los años siguientes, especialmente entre 1917 y $1922 .{ }^{19}$ También es importante considerar que en esos años posteriores a 1910 el conflicto obrero estuvo menos centrado en el anarquismo que había sido construido como el agente patógeno peligroso en la primera década del siglo.

En relación con las medidas de excepción permanentes que consideramos aquí, la célebre "Ley de Residencia" fue aprobada en 1902, como reacción a las grandes huelgas que paralizaron la actividad agroexportadora a fines de ese año. La ley fue sancionada como medida urgente, casi sin discusión parlamentaria, aunque con la oposición vehemente de unos pocos senadores y diputados. Su texto retomaba, en realidad, un proyecto previo, preparado por el senador Miguel Cané en 1899, que no había sido aprobado en su momento pero que bajo la percepción de urgencia generada por la parálisis laboral fue rápidamente reactivado. ${ }^{20} \mathrm{Al}$

La huelga portuaria de 1904 fue enfrentada con presión patronal y militar (Caruso, en prensa); la huelga general de 1907 iniciada en Rosario fue respondida con acciones policiales y militares y luego la Municipalidad local anuló la disposición que había provocado el conflicto (Belkin, 2015). La huelga de inquilinos de ese mismo año (que involucraba sectores obreros como principales participantes) se enfrentó con represión directa (Suriano, 1983).

19. Para la aplicación de estado de sitio en la historia argentina, véase Ziulu (2000).

20. A diferencia de los proyectos previos, el aprobado en 1902 no incluía el encarcelamiento para los reincidentes igual que en otros países donde eran aplicadas fórmulas similares, la ley preveía la expulsión por orden del poder ejecutivo de los extranjeros cuya conducta comprometiera la seguridad nacional o el orden público, para extranjeros condenados o perseguidos por tribunales extranjeros, o para aquellos cuyos antecedentes "autoricen a incluirlos" en esos riesgos. Además, establecía que quienes fueran expulsados tenían tres días para salir del país o podían ser encarcelados hasta que se concretara la partida. ${ }^{21}$ Como plantearon innumerables voces de la época y durante muchas décadas, esta ley podía ser considerada de excepción porque violaba sistemáticamente varios derechos constitucionales al establecer penas (la expulsión) por decisión del poder ejecutivo y sin derecho a juicio para el acusado, concentrar poderes excepcionales en la autoridad presidencial (que ni aún bajo estado de sitio puede otorgar penas ni expulsar personas), y violar la igualdad ante la ley de extranjeros y nativos que poseen los mismos derechos civiles en tanto habitantes del territorio nacional. A pesar de sucesivos intentos, especialmente en 1904 y 1946, la ley sólo fue derogada en $1958 .^{22}$

Las evidencias disponibles sobre el uso de la Ley de Residencia durante la década muestran que fue intensamente aplicada en las coyunturas de estado de sitio y escasamente en momentos de menor conflictividad obrera generalizada. Por ejemplo, hubo 88 decretos de expulsión entre noviembre y diciembre de

que volvieran al país una vez expulsados (Pavón, 1913).

21. Ley 4144, 23 de noviembre de 1902. BORA.

22. Para una completa exposición de los argumentos de inconstitucionalidad, véanse las exposiciones de Alfredo Palacios en el intento de derogación de 1904. CDDS, 18 de julio de 1904. BCN, Buenos Aires y otros escritos de juristas, especialmente, Sánchez Viamonte (1956). 
1902 (es decir, durante el estado de sitio) y sólo 3 en 1903; 86 casos en los primeros meses de 1905 (durante el primer estado de sitio) y sólo 2 en 1906; 41 en 1908 y 251 en noviembre de $1909 .{ }^{23}$ Esto sugiere que aunque la ley tuvo un uso asistemático y poco eficaz -aspecto sobre el que insisten diversos autores y ya señalaban actores de época (Albornoz, 2017; Barry, 2009) - fue clave e intenso su uso combinado y articulado con las medidas de excepción coyuntural.

Por su parte, la "Ley de Defensa Social" fue aprobada pocos años después, también de manera urgente y bajo el efecto de un atentado anarquista que hizo explotar una bomba en el teatro Colón el 26 de junio de 1910 y dejó varios heridos. La nueva ley intentaba profundizar la de 1902 -considerada insuficiente y poco efectiva- detallando mejor, a través de 35 artículos, una serie de delitos y penando actos que no estaban comprendidos en la anterior, por ejemplo, la propaganda, la agitación, las reuniones y asociaciones con fines anarquistas, el uso de emblemas de ese tipo y la fabricación y uso de explosivos. En este caso la ley identificaba claramente como enemigos a distintas "clases de extranjeros" (dentro de los cuales solo definía con mayor precisión a "los anarquistas y demás personas..."), y a los argentinos que cometieran los delitos indicados. Para los extranjeros prohibía la entrada y residencia al país, y penaba a empresarios o transportistas que los trasladaran; para los argentinos además de las penas de cárcel se retiraba la ciudadanía argentina y los derechos políticos. La ley incorporaba la pena de muerte para los responsables de atentados de bomba en que

23. Copiador Anarquismo. Departamento Archivo Intermedio, Archivo General de la Nación, Buenos Aires. Agradezco a Martín Albornoz su enorme generosidad para haber compartido conmigo. murieran personas - modificando incluso una parte de las restricciones con que esa pena era admitida por el Código Penal vigente- y castigaba con confinamiento a los reincidentes. $\mathrm{La}$ ley también penaba la instigación violenta a la huelga. ${ }^{24}$

Como se vio en ambos casos, estas leyes de excepción permanentes combinadas con las medidas temporales muestran un mismo proceso político: a partir del sentimiento de amenaza frente a un conflicto vinculado al mundo laboral, o a sus actores, se construía el argumento de la necesidad y urgencia de las políticas de excepción como única solución posible, y una vez en ese punto, la resolución represiva articulaba medidas de efectividad rápida contra el conflicto inmediato con estrategias de excepción de largo plazo.

\section{De la inmigración a la perturbación}

E1 22 de noviembre de 1902, mientras las páginas de la prensa otorgaban cada vez más espacio a noticias alarmantes sobre el crecimiento del movimiento de huelga y su ampliación a diversos gremios y actividades, el Senador Pérez, presidente de la Comisión de Negocios Constitucionales del Senado presentó brevemente el proyecto de "Ley de Residencia", disculpándose por la falta de tiempo para que la comisión analizara a fondo la medida. Sus palabras sintetizan casi todos los argumentos

24. Ley 7029, 30 de junio de 1910, BORA. La pena de muerte estaba admitida con muchas restricciones en el Código Penal de 1886 y fue eliminada en la reforma de 1916. La "Ley de Defensa Social" tuvo fuertísimos críticos, pero casi todos consideraban que era necesaria una legislación que garantizara la defensa social contra el anarquismo, véase Pavón (1913) y Dufey (1913). 
relevantes del gobierno y de quienes estuvieron a favor de la norma, pero sobre todo, reúnen buena parte de las representaciones de las élites sobre los conflictos obreros como amenazas al orden social -argumento que sostenían incluso quienes se oponían al uso de medidas de excepción-. ${ }^{25}$

Se trata de una ley eminentemente política, de una ley de excepción y de prevención, destinada a evitar que ciertos elementos extraños vengan a turbar el orden público, a comprometer la seguridad nacional; (...) se trata de (...) salvar la tranquilidad social, comprometida por movimientos esencialmente subversivos, que no son los movimientos tranquilos del obrero trabajador, ni del extranjero honrado, que buscan en la huelga el medio de satisfacer justos anhelos; sino agitaciones violentas, excesos y perturbaciones producidas por determinados individuos que viven dentro de la masa trabajadora para explotarla, abusando así de la hospitalidad generosa (...) no se trata de dictar una ley contra las huelgas (...); se trata de evitar los abusos, de prevenir hechos criminales que se producen a la sombra de la huelga, se trata de salvar a la sociedad de esos estallidos anárquicos que comprometen tan graves intereses (...) Entonces es natural que el poder ejecutivo esté armado de esta ley de defensa para conjurar esos peligros asegurando en todo tiempo la tranquilidad y el bienestar de la comunidad. ${ }^{26}$

El argumento aquí presente y que se repetirá durante toda la década es el intento de construir diferenciaciones entre las huelgas y los trabajadores con motivos "legítimos" y

25. Es el caso, por ejemplo, del diputado Emilio

Gouchon en 1902. CDDS, 22 de noviembre de 1902, p. 348.

26. Senador Pérez, CDDS, 22 de noviembre de 1902, p. 657. los "perturbadores profesionales" que generan conflictos de índole "subversiva" y que requieren otros medios de resolución. Como lo reiteró el senador Pellegrini en el debate del estado de sitio de 1902, dos días después de la aprobación de la "Ley de Residencia":

Las alteraciones que vive la ciudad y el país son parte del progreso. (...) Los conflictos empiezan por una huelga parcial, casi siempre justa en sus causas (...) empiezan a aglomerarse otros elementos que, aprovechando un terreno preparado, buscan conmover el orden social (...) y entonces los gobiernos se ven obligados a recurrir a medidas extraordinarias (...) Para proteger a los obreros, para separar de este elemento sano y ordenado todos estos otros elementos de explotación, de anarquía y de desorden que solo buscan el logro de sus intereses (...) haciendo servir al honrado trabajador de instrumento y de víctima de esos propósitos subversivos. ${ }^{27}$

También el oficialista diario $L T$, en medio de la discusión parlamentaria de 1902, argüía: "toda libertad para el obrero pacífico; represión severa contra los agitadores que fomentan el desorden y el crimen". ${ }^{28}$ En definitiva, se confinaba la protesta obrera a un problema de "perturbadores" cuando sus límites trascendían las dimensiones toleradas. En cuanto a los agentes "patógenos" y "perturbadores", como es ya conocido, éstos se recortaban en torno a dos alteridades distintas pero congruentes: los inmigrantes extranjeros y los anarquistas, cuya expulsión era entonces "profiláctica":

Entre nosotros el elemento extranjero es

27. Senador Pellegrini, CSDS, 24 de noviembre de 1902, p. 679 .

28. (22 de noviembre de 1902). La Tribuna (LT). BCN, Buenos Aires. 
una fuerza poderosa; los extranjeros forman verdaderas islas étnicas que no acaban de incorporarse a nuestro organismo nacional; y un fermento de su mismo origen que viene a este país puede producir verdaderas perturbaciones, verdaderos prejuicios. (...) Además no puede existir entre nosotros, por lo menos salido de nuestras entrañas, ese germen de descomposición a que me refiero. (...) Yo no creo que existan argentinos anarquistas; si existieran no pediría contra ellos ninguna pena, los mandaría, simplemente, al manicomio. ${ }^{29}$

De esta manera, también los extranjeros eran clasificados entre aquellos pacíficos que venían a trabajar y a contribuir a la grandeza del país y aquellos otros "ingratos" que no estaban "arraigados en la patria" o que "no tiene[n] la comunión de nuestras glorias". ${ }^{30}$ Como han mostrado diversas investigaciones, ello permitió construir rápidamente la figura del extranjero peligroso como amenaza al orden social, que se expresaba en la idea misma de que el Estado tenía derecho a la expulsión de los indeseables (Domenech, 2015; Scarzanella, 2015), tan frecuente en muchos países por la misma época. Sin embargo, esta distinción entre nacionales y extranjeros se fue modificando a lo largo de la década a medida que la amenaza perfiló sus contornos. Pronto se hizo evidente que los agentes de perturbación no eran solo extranjeros sino también argentinos, de manera que los elementos "patógenos" e "infecciosos" estaban ya dentro del territorio. Por eso, empezó a demandarse una ley más completa y eficaz

29. Diputado Mugica, CDDS, 22 de julio de 1904, p. 589.

30. Ministro del Interior, CDDS, 13 de mayo de 1910, p. 55-56.

40 que la de residencia - tal como proponía ya en 1904 el diputado Carlos Delecasse durante el debate para derogar la ley promovido infructuosamente por Alfredo Palacios-. ${ }^{31}$

A pesar de estas variaciones, lo que interesa resaltar es el peso de un discurso que definía fronteras entre el adentro y el afuera: si esas fronteras parecen objetivamente definibles en torno a la condición extranjera -el inmigrante internacional-, a eso se yuxtapuso otra distinción metafórica de base biologicista -el agente infeccioso que entra a un cuerpo sano representado por la Nación-. El paso entre uno y otro discurso conlleva la definición de una esencia, la Nación, que como veremos, es central para entender el uso de la excepcionalidad jurídica.

\section{¿Solo anarquistas?}

La definición de los contornos del enemigo se verá acelerada y precisada a partir de 1909 , con los atentados contra Falcón y la bomba en el Teatro Colón el 26 de junio de 1910, entre otros episodios. ${ }^{32}$ Estos hechos justificarán el particular recorte del anarquismo como elemento insano a expulsar de la sociedad "sana" -es decir, el orden instituido imagina-

31. CDDS, 29 de julio de 1904, p. 686. También advierten en esa dirección varios juristas de la época. Véase: Dufey (1913).

32. Estos episodios no fueron los únicos, hubo además sendos atentados en 1905 y 1908 contra los presidentes Quintana y Figueroa Alcorta y contra el cónsul español en Rosario en 1909. Como muestra Suriano, estos hechos fueron episódicos y no permiten sostener la idea del anarquismo como acción terrorista en la Argentina. En contraste, la violencia no dejó de generar contradicciones políticas y siempre estuvo presente en la retórica ácrata como un resultado justificado de las injusticias sociales (Suriano, 2001). 
rio- y del Estado Nación -es decir, el orden político territorial-, que marcan las medidas de excepción de 1909 y 1910. En ese sentido, el acento creciente en esta tendencia política permitió su desplazamiento de un tema incluido como parte de la cuestión social y obrera a un asunto de criminalidad o delincuencia focalizada. Como señala Ricardo Martínez Mazzola (2003), la mirada liberal reformista tendió a identificar los elementos atendibles y comprensibles de la demanda social con el socialismo y los patógenos con el anarquismo. Ello permitió que el tema fuera abordado con las nuevas teorías criminalísticas científicas. $\mathrm{El}$ anarquismo, en particular, fue visto como una patología física-psíquica hereditaria y predispuesta al crimen, e incluido en las nuevas teorías de la defensa social (Suriano, 2001; Zimmermann, 1995). Este desplazamiento es claro y visible y encontró justificación en el proyecto político-cultural del anarquismo -su prédica contra las instituciones pilares del orden liberal y su apelación a la violencia-, los atentados de aquellos años y el temor de las élites en reacción a hechos violentos de los ácratas europeos -contexto muy presente en los debates y prensa de la época-.

Pero lo que interesa resaltar no es tanto esta construcción en torno al anarquismo como sus consecuencias más vastas: el nuevo recorte del enemigo permitió justamente desdibujar detrás de él la cuestión social y obrera subyacente, de la que formaba parte el movimiento ácrata y, a la vez, generar una legislación global que afectaba a sectores inmigrantes (fundamentalmente pobres) y trabajadores en su conjunto. En otros términos, se disoció cuestión social/ obrera y cuestión política y se identificó esta última con un enemigo cuyas características lo hacían "objetivamente" peligroso para la "seguridad nacional", permitiendo así legitimar políticas coercitivas. Con ello se construía un dispositivo legal y simbólico que también era usado para enfrentar la conflictividad social y laboral más amplia y de más largo plazo. Sin embargo, los motivos subyacentes de vez en cuando asomaban con claridad. En 1905, ante un nuevo ciclo de huelgas, $L N$, que durante toda la década cuestionó el uso de leyes de excepción tanto como al anarquismo y las huelgas "no legítimas", terminó señalando con alarma que las causas de la huelga "no nacen de simples incitaciones de agitadores ó anarquistas, porque por grande que sea la influencia de éstos, la masa obrera no se mueve con la espontaneidad y uniformidad que hoy lo hace, sino cuando la impulsa un móvil de extraordinario poder [el salario]". ${ }^{33}$

Así, los cinco periodos de estado de sitio considerados (incluyendo el primero de 1905) fueron la ocasión de intensas políticas represivas sobre los sectores trabajadores e inmigrantes, con el avasallamiento sistemático de derechos sobre diversos sectores políticos del mundo obrero (y ni siquiera exclusivamente, volveremos sobre esto). Bajo el paraguas de la excepción se desarticularon los procesos de huelga, se detuvieron cientos de trabajadores de distintas extracciones políticas, se allanaron domicilios, se militarizaron los espacios laborales, se deportaron inmigrantes, se detuvieron y confinaron otros, se clausuraron y/o destruyeron locales obreros, se censuró o prohibió la prensa de ese origen $-L P$ y $L V$ y otras publicaciones dejaron de aparecer después de cada medida de estado de sitio- ${ }^{34}$. También,

33. (3 de octubre de 1905). LN. Biblioteca Nacional, Buenos Aires.

34. Véase el resumen de lo sucedido en distintos periodos de estado de sitio, por ejemplo (8 de enero de 1906). $L a$ Prensa. BN, Buenos Aires; (1 de febrero de 1906). La Protesta (LP). APA; (30 de junio de 1910). LV. APA. 
se prohibieron las reuniones y la libertad de prensa en general, ya que ningún medio podía informar sobre los hechos ni sobre el propio estado de sitio -situación que La Prensa y $L N$ denunciaban con frecuencia-. Particularmente vívidos son los relatos socialista y anarquista sobre el asalto a las oficinas del Partido Socialista, la destrucción e incendio de las instalaciones de $L V, L a$ Batalla y $L P$, así como los locales de otros gremios y las manifestaciones contra extranjeros y anarquistas al iniciarse el estado de sitio de $1910 . .^{35} \mathrm{LV}$ denunciaba que el estado de sitio no era tanto para reprimir anarquistas como para terminar las huelgas, reprimir y encarcelar sistemáticamente a trabajadores y asalariados, impedir la participación socialista en las elecciones (en las municipales bonaerenses de 1902), y prohibir otras acciones partidarias como reuniones y propaganda. ${ }^{36}$ En esa línea y para la coyuntura de

Aunque socialismo y anarquismo fueron muy afectados en todo su funcionamiento, hay que señalar que las medidas tendieron a ser más largas y más intensas contra el segundo. En algunos casos La Vanguardia pudo reaparecer antes de que el estado de sitio se levantara. La Protesta denunció con frecuencia esta diferencia de trato así como la rápida liberación de muchos detenidos socialistas a diferencia de los anarquistas (31 de enero de 1903). LPH. APA.

35. (30 de septiembre de 1910). $L V$. y (20 de mayo de $1910)$ y ss. $L P$. Esas informaciones, en general, no eran dadas por la prensa comercial, bajo el argumento de que el estado de sitio no lo permitía. Hubo excepciones como La Prensa que publicó un extenso detalle de los abusos cometidos al finalizar el estado de sitio de 1905.

36. (29 de noviembre de 1902); (27 de diciembre de 1902); (27 de mayo de 1905); (14 de enero de 1910), entre otros. $L V$. Estas crónicas incluyen la lista de "atropellos", detenciones, malos tratos y vigilancia a miembros del partido socialista, así como la clausura de todos los centros socialistas, la prohibición de su periódico (que se editaba clandestinamente burlando el control policial) y otros medios locales. También se denuncian abusos patronales en las relaciones con obreros y denuncias a la policía de obreros "díscolos".

42
1902, Marcela Aspell (1979) ha demostrado el peso de la conflictividad laboral como trasfondo de la "Ley de Residencia". Asimismo, Barry (2009) ha mostrado que estos periodos de excepción fueron de intensa actividad de la Policía y de desarrollo de sus áreas especializadas en la persecución, vigilancia y represión de diversas corrientes políticas del mundo obrero y ello en escala ascendente dentro del periodo. Aunque esta policía fuera aún una institución en formación, mal equipada y poco eficiente, es un dato elocuente el aumento de las cifras de fichaje de antecedentes de individuos por parte de la División de Investigación. Si en 1905 había 13.344 fichados, en 1909 eran 42.764 y en 1910 había pasado a 184.922 (Barry, 2009).

En síntesis, no se trata tanto de destacar el proceso de criminalización del anarquismo, que ya ha sido bien estudiado, sino en sentido inverso de insistir en lo que ese proceso habilita en términos sociales y políticos. La operación realizada en torno al anarquismo (recorte, abstracción, criminalización) es, justamente, una operación metonímica habitual de las construcciones simbólicas en las políticas de excepción, pero detrás de ella se estructuró también la respuesta política al conflicto obrero y social cuando fue percibido como una amenaza grave ${ }^{37}$ Sin olvidar que ni siquiera la metonimia era totalmente necesaria, en la medida en que el anarquismo, efectivamente, representaba una buena parte de la acción obrera organizada. En ese sentido, la normativa de esta primera década de siglo muestra al desnu-

37. Hemos observado el uso de estas metonimias para las décadas del '50 y el '70 (Franco, 2012a y 2012b). De hecho, podría hacerse un claro paralelo con la figura de la subversión en las décadas del ' 60 al ' 80 , con la diferencia que ésta última era de por sí una construcción genérica y el anarquismo era la autodefinición de una fuerza política definida. Sin embargo, los usos desde el poder de ambas figuras presentan notables parecidos. 
do la fuerza de la percepción sobre la cuestión obrera y social como amenazas totales al orden, y que se activaba en los momentos de conflicto más álgido. ${ }^{38}$ Que esas amenazas se resolvieran por vía de la excepcionalidad jurídica es el dato clave que aquí nos interesa poner en evidencia. Lejos de ser solo un instrumento de época habitual en un régimen oligárquico, el uso recurrente del estado de sitio muestra las percepciones epocales del conflicto -y también las diferenciaciones intraélite sobre el tema-.

\section{La excepcionalidad jurídica como derecho a la autodefensa}

En reiterados casos, los estados de sitio fueron usados para responder a conflictos obreros y movimientos de huelga que las élites veían crecer y afectar progresivamente todos los resortes de la economía. Así los miembros del gobierno y numerosos parlamentarios explicitaban su uso legítimo desnudando no sólo la normalidad de la excepción, sino la centralidad de la actividad económica agroexportadora identificada como "interés nacional":

Se la traiciona [a la República] cuando se conspira contra ella en toda otra forma, cuando se conspira contra la estabilidad nacional, (...) contra sus intereses permanentes, cuando se hace alarde de un propósito decidido y firme de evitar que la riqueza pública se desenvuelva (...) El estado de sitio (...) no limita ningún derecho legítimo, no restringe ninguna libertad. ¡El estado de sitio que el poder ejecutivo pide (...) es sencillamente un instrumento de gobierno,

38. En la misma línea, Eugenia Scarzanella (2015) muestra como en 1910, la persecución del crimen urbano no se explicaba por la condición inmigrante o étnica de los arrestados, sino por variables sociales y de clase. un resorte que todos los gobiernos de la tierra usan para defender a la sociedad de los desordenados. (...) ¡Pero no contra los desordenados políticos, no! Contra los que no permiten que la industria funcione, que el comercio haga sus operaciones.

Aquí no se trata de movimientos políticos; no habrá una imprenta cerrada; no habrá una reunión impedida (...) Lo único que habrá será la facultad dada al poder ejecutivo de reprimir cuando lo estime necesario, todo desorden, todo avance contra el derecho de los demás. ${ }^{39}$

En 1909, desde la oposición al oficialismo, el diario La Prensa proclamaba que la huelga general contra la represión del $1^{\circ}$ de mayo ya no era una huelga obrera "propiamente dicha" sino "agitaciones belicosas armadas con subversión del orden público" que generan "un estado de guerra". ${ }^{40}$ Unos y otros argumentos, al construir la gravedad extrema de la amenaza velaban tras las consideraciones de necesidad y obligación el carácter político de toda acción de gobierno. Este mismo dispositivo puede apreciarse en las palabras del senador Pellegrini en 1902:

Pues cuando el poder ejecutivo se ve obligado a sacar de sus cuarteles al Ejército de la Nación y lanzarlo en las calles de la ciudad à objeto de defender los derechos de los ciudadanos, cuando hay que apelar a este recurso peligroso porque las fuerzas policiales ordinarias han sido desbordadas ó son insuficientes para contener los elementos perturbadores, existe el hecho visible y palpable

39. Diputado Varela Ortiz, CDDS, 7 de octubre de 1905, p. 392.

40. (11 de mayo de 1909). La Prensa. Cit. en Frydenberg y Ruffo (2012, p. 173). 
que importa una amenaza a la paz pública. ${ }^{41}$

La oposición al uso de leyes de excepción estuvo reducida a muy pocos pero enérgicos congresistas a lo largo del periodo. La crítica se centró en sus aspectos anticonstitucionales y justamente en su carácter de leyes de emergencia. Lo mismo sucedió con los estados de sitio, objetados por tratarse de medidas extremas que debían ser aplicadas en situaciones de conmoción interna y no a huelgas obreras. En la mayoría de los casos se sostuvo que los recursos represivos habituales de la policía eran suficientes, que en otros países las grandes huelgas no se enfrentaban con estado de sitio, y que esta medida era una extralimitación parlamentaria que dejaba a los ciudadanos sin derechos y a merced del poder. ${ }^{42}$ Además de los propios sectores afectados, las leyes permanentes fueron duramente objetadas por diversos juristas desde 1902 y 1910 en adelante, y por los diarios opositores al Partido Autonomista Nacional (en adelante, PAN), La Prensa y $L N .^{43}$ En todos los casos, quienes las promovieron reco-

41. Senador Pellegrini. CSDS, 24 de noviembre de 1902, p. 679 , resaltado de la autora.

42. Sostuvieron estos argumentos, entre otros, el diputado Castellanos ante el estado de sitio de 1902. CDDS, 21 de noviembre de 1902; los diputados Argerich, Meyer Pellegrini y Naón ante la medida de octubre de 1905. CDDS, 7 de octubre de 1905; también Rodríguez Jurado en el debate del estado de sitio en 1910. CDDS, 13 de mayo de 1910.

43. Sobre la oposición de La Nación a las medidas de estado de sitio y de excepción, véase por ejemplo (6 de octubre de 1902). $L N$, señalando que en ningún país del mundo se declara una medida de ese tipo por huelgas obreras; denunciando abusos y uso del estado de sitio (25 de noviembre de 1909). $L N$; (13 de mayo de 1910). $L N$, Biblioteca Nacional, Buenos Aires. Para La Prensa, denunciando los abusos del estado de sitio, por ejemplo, (24 de noviembre de 1902); para la "Ley de Residencia" (1 de enero de 1903) y (11 de octubre de 1905). La Prensa. Biblioteca Tornquist, Buenos Aires. nocían su carácter excepcional y político, invocaban su uso en otros países y afirmaban que la situación así lo exigía, pero negaban los aspectos en los cuales esas leyes violaban principios jurídicos fundamentales, como la violación del derecho a defensa en juicio, la igualdad de derechos civiles para todos los habitantes (sin distinguir extranjeros y ciudadanos argentinos) y la prohibición constitucional de que el poder ejecutivo ejerciera otros poderes y aplicara penas. ${ }^{44} \mathrm{El}$ diputado Argerich, por ejemplo, sostuvo lo siguiente en el intento de derogación de la "Ley de Residencia" en 1904:

Entiendo que [la "Ley de Residencia"] es una ley de policía, de profilaxia y de higiene social, acerca de la cual están aquí fuera de lugar (...) las largas consideraciones sobre su inconstitucionalidad. (...) Dada la composición del parlamento y su carácter de cuerpo político, el congreso, sujeto a conjurar peligros y a remediar con urgencia graves cuestiones y conflictos sociales, su suprema inspiración es la razón de estado [sic]. (...) el debate acerca de su inconstitucionalidad carece de importancia. ${ }^{45}$

Estos argumentos están en línea con las teorías del derecho del Estado a la defensa social, concepto fundamental en las nuevas teorías de criminología científica de comienzos de siglo, que sostenían el derecho de la sociedad a defenderse de sujetos peligrosos a través del castigo penal, de manera preventiva o represiva (Dufey, 1913; Ingenieros, 1911; Pavón, 1913; Zimmermann, 1995). Por un lado, como se señaló antes, ello permitía identificar al

44. Por ejemplo, J.V. González, Ministro del Interior, CDDS, 22 de noviembre de 1902 y dictamen de la Comisión de negocios constitucionales, CDDS, 18 de julio de 1904.

45. Diputado Argerich, CSDS, 27 de julio de 1904, p. 651. 
anarquismo como una forma de delincuencia y asociarlo con los criminales comunes, desconociendo la dimensión social del conflicto. A su vez, por otro lado, también permitía transformarlo en un hecho político (en tanto se lo disociaba de las protestas y demandas obreras) contra el cuál parecían válidos otros medios discrecionales del poder. Al desechar los argumentos sobre la legalidad de la ley y colocar el acento en la defensa social y la autopreservación de la sociedad como cuestiones por encima del orden legal mismo, el principio de la necesidad permitía elidir no sólo el acto político sino también sus agentes responsables.

En los casos analizados esta operación aparece sellada con la construcción de esa necesidad en nombre de valores esenciales. Así, por ejemplo, el Ministro del Interior en 1905, al pedir la sanción del estado de sitio señalaba que estarían garantizados los derechos constitucionales de quienes contribuyeran con su trabajo a la riqueza del país. ${ }^{46}$ En 1910, el diputado Olmedo diría más extensamente:

Este es un estado de sitio protector para todos los argentinos; será en favor y beneficio de todos los argentinos; de todos los sentimientos, de todas las ideas más nobles que puede encarnar el espíritu, las tendencias y los intereses de una nación. Tal estado de sitio (...) no tendrá otro alcance que establecer -por una ley de excepción sin duda, pero por una ley necesaria (...)- el poder inmenso de la nación para gobernarse a sí misma libre de toda presión extraña (...) aún de las pasiones rojas. ${ }^{47}$

46. CSDS, 7 octubre de 1905, p. 15.

47. Diputado Olmedo, CDDS, 13 de mayo de 1910, p. 62.
Como se ha señalado muchas veces, los profundos cambios sociales y políticos de la época-percibidos como amenazas al orden- más aún en el contexto de la celebración del Centenario, fueron la base de un creciente nacionalismo cuyo mayor peso político llegaría en las décadas siguientes (Zimmermann, 1995). No obstante, la asociación entre actividad agroexportadora, orden social y Nación, por un lado, y entre excepción y necesidad, por el otro, permite entender la cadena de sentidos por la cual las huelgas obreras que amenazaban la exportación agropecuaria fueron evitadas con leyes de excepción. Si el peligro concreto y su origen geográfico dejaban de importar para ser reemplazados por un valor esencial amenazado (la condición nacional), ese valor debía ser defendido con el máximo recurso: el orden constitucional poniéndose en juego a sí mismo. La figura del "argentino" que no sería afectado por las leyes de excepción define así tanto una frontera identitaria como un sistema de privilegios (Andrenacci, cit. en Pacecca, 2003). Como señala María Inés Pacecca (2003), la nacionalidad aparece entonces como un "vinculo natural y esencial con un territorio" y ello autoriza a quienes portan esa nacionalidad a ser "enunciadores legítimos de lo político en ese territorio" (p. 128). Este argumento era claro en la "Ley de Residencia" aplicada a los extranjeros que carecían de ciudadanía política y que quedaban desprotegidos al perder derechos básicos, pero siguió operando en las leyes de excepción siguientes donde lo extranjero no era definido por criterios geográficos sino esenciales (su no pertenencia a la Nación). Más aún, lo argentino se definió invirtiendo el argumento: la excepcionalidad no podía afectar a los argentinos porque éstos, si eran argentinos, no atacaban el orden social. De esta manera, la circularidad del argumento nacio- 
nalista quedaba consagrada, y lo hacía a través de legislación de excepción, cuya circularidad (jurídica) es similar: la legislación de excepción supone que el orden del derecho se suspende a sí mismo para conservarse.

A tal punto este dispositivo simbólico fue efectivo y compartido que medios como $L a$ Prensa, alineados con el sector reformista de la élite y opositor a las medidas de excepción, aceptaron enfáticamente el estado de sitio de 1910 porque consideraron que la huelga era "política" y afectaba el sentimiento patriótico. $L N$, ese mismo año terminó aprobando la "Ley de Defensa Social" contra "el monstruo engendrado en las clases inferiores por la acción disolvente de las malas sombras [...] Pagamos [como Nación] el tributo que es menester por el derecho de ir adelante y de ocupar un puesto en la vanguardia". ${ }^{48}$

Un dato clave para entender la dimensión del conflicto social construido como "conflicto nacional" a lo largo de toda la década, pero muy particularmente en 1910, es que los ataques a los partidos y prensa obreros de ese último año no fueron solo producto de la acción oficial, sino de grupos civiles de jóvenes en nombre de "la patria". Así, $L V$ relata la acción de "jóvenes universitarios" y "burgueses" que, junto con la policía, destruyeron con voracidad y exaltación todas las instalaciones partidarias, bibliotecas, cafés y comercios, y persiguieron a anarquistas, socialistas y extranjeros al grito de "viva la patria". ${ }^{49} \mathrm{La}$ información es importante porque permite apreciar que los estados de excepción jurídica no sólo liberan energías estatales, sino que tienen un poder mayor en su capacidad política performativa que emana del agente

48. (28 de junio de 1910). $L N$.

49. (30 de septiembre de 1910). $L V$; Suriano (2001).

46 enunciador tal como este es percibido: el Estado. En efecto, su potencia simbólica en torno a la necesidad de defender al orden y la nación amenazados se extiende para habilitar otras formas de la violencia social y política por fuera de la acción estatal. La amenaza que las políticas de excepción construyen a partir de la relación entre necesidad y esencialidad es tan potente que puede desplazar el principio del Estado como monopolio de la fuerza. En otros términos, las políticas de excepción expresan y son resultado de construcciones sociales que las preceden en la misma medida en que las crean y alimentan. No es un dato menor la suerte ascendente que tendrán los grupos de derecha y nacionalistas en su persecución de sectores obreros e inmigrantes en las décadas siguientes y bajo el amparo del Estado. ${ }^{50}$

Las leyes de excepción de la época suponían, al menos teóricamente, vastos espacios de suspensión de toda juridicidad y se activaron especialmente en coyunturas precisas. En esa línea, aunque su uso no fuera regular ni eficaz, hubo múltiples denuncias parlamentarias por la aplicación de la "Ley de Residencia", por ejemplo, entre obreros y dirigentes socialistas. ${ }^{51}$ Como muestra un memorándum policial de 1904, el margen de arbitrariedad era amplio y la aplicación de la ley quedaba en manos de criterios policiales laxos como pronunciar "discursos subversivos", no tener oficio o participar de un sindicato (Zimmermann, 1995, p. 162163). En esa misma tónica, la apropiación policial del concepto de defensa social se impuso por sobre el análisis de las responsabilidades

50. Sobre esto véase en particular los trabajos de McGee Deutsch (2003).

51. Diputado Palacios, CDDS, 27 de mayo de 1904. 
individuales y permitió un uso amplio de los poderes represivos y el abuso en la aplicación de las leyes de excepción (Zimmermann, 1995, p. 137)..$^{52}$

También interesa destacar que esta legislación ofreció instrumentos de persecución y gestión del conflicto político dentro de las propias élites, como no se cansaron de denunciar desde la oposición al PAN los diarios $L N$ y $L a$ Prensa. Estos medios cuestionaron la censura y los abusos políticos y reclamaron que la aplicación de las medidas no quedara en manos de policías y administraciones locales porque eran utilizadas para resolver conflictos políticos internos en diversas provincias. ${ }^{53}$ Por lo tanto, aquí emerge otro rasgo importante de las medidas de excepción en cuanto a su uso discrecional y la liberación de una fuerza cuyo uso no puede garantizarse de antemano. En estos casos, la regulación del conflicto político se dirigió no sólo contra los sectores obreros y populares sino también como mecanismo de regulación intraélite -de la misma manera que en febrero de 1905 se invirtió el orden y el

\section{Aunque las cifras no resultan enormes, como consecuencia de la ley, entre 1902 y 1911 se expulsaron 539 extranjeros, casi la mitad de ellos en 1909 (Barry, 2009). La ley fue luego intensamente usada en la década del cuarenta, para la persecución y deportación o encarcelamiento de obreros y líderes sindicales, tal como lo denunció Silvio Frondizi. Véase Archivo Silvio Frondizi. Biblioteca Nacional, Buenos Aires; y Nazar (2008).}

53. (14 de octubre de 1905). La Prensa. Biblioteca Tornquist, Buenos Aires; y días subsiguientes en particular sobre la situación en Mendoza. El propio diario La prensa fue atacado y censurado en algunas ciudades (17 de octubre de 1905). La Prensa. Entre 1902 y 1903 denunció duramente el uso dado al estado de sitio y a "Ley de Residencia" (1 de enero de 1903). La Prensa y (6 de mayo de 1903). La Prensa. También véase Aspell (1979) sobre denuncias parlamentarias por el uso de la ley contra la oposición política en 1902. conflicto intraélite permitió también regular el conflicto obrero a través del estado de sitio-.

\section{Conclusiones}

En la Argentina, el estado de sitio, y las medidas de excepción en general, fueron un recurso habitual para la gestión del conflicto social y político de cualquier tipo y eso supone su uso normalizado como instrumento político sin demasiadas particularidades. Sin embargo, en esta primera década del siglo $\mathrm{XX}_{2}$ esas medidas se usaron mayoritariamente para resolver conflictos del mundo del trabajo (entendido el anarquismo como parte de ello). A su vez, en las décadas siguientes no volvieron a usarse hasta 1930, momento en que fueron nuevamente reutilizadas para disciplinar a otros sectores en conflictos políticos strictu sensu.

De esta manera, el estudio de las medidas de excepción de la primera década del siglo permite inscribirlas como parte del repertorio específico de un periodo- de los mecanismos utilizados por ciertas áreas del Estado (en este caso, el poder ejecutivo y legislativo) con función preventiva o represiva. El tipo de instrumentos aplicados - de suspensión del orden legal, es decir, colocando sujetos o coyunturas por fuera del Estado de derecho- y las representaciones que las sostuvieron -centradas en la delimitación de diversas formas de exterioridad de las amenazas-, muestran claramente la dificultad de las élites de incorporar dentro del país por ellas definido el conflicto social y obrero en la primera década del siglo, en particular, cuando éste era percibido como un riesgo que sobrepasaba aquello que estaba en proceso de aceptación incipiente. En esta dificultad, y en el propio discurso anticapitalista 
y antiburgués de los sectores anarquistas -colocándose por fuera del orden dado-, seguramente hay una clave explicativa para entender por qué el instrumento de gobierno fueron las medidas de excepción y no otras formas.

El hecho de que el conjunto de la legislación de excepción se concentrara -con matices y variaciones- en la definición del extranjero anarquista o del anarquista tout court como la amenaza al orden social supuso una serie de operaciones político-simbólicas que deben ser distinguidas de la presencia fáctica del anarquismo e incluso de sus acciones violentas. En particular, porque esas operaciones simbólicas y la construcción de figuras de alteridad peligrosa son justamente el mecanismo simbólico central de las políticas de excepción, y también la garantía de su efectividad política y su legitimidad social. Los mecanismos puestos en funcionamiento en el caso estudiado -la construcción de enemigos internos- y la matriz representacional que las sostuvo -la construcción de alteridad confundida con exterioridad y extranjeridad nacional- tuvo luego larga persistencia en el siglo XX argentino. Esas mismas operaciones simbólicas también ayudan a entender por qué muchas miradas posteriores sobre la acción del Estado recayeron sobre el anarquismo y menos sobre lo que muestran el conjunto de las políticas de excepción aplicadas.

$$
\propto \tilde{e} \propto
$$

Recibido: 01-11-2018

Aceptado: 01-03-2019

Publicado: 04-06-2019 


\section{Referencias Bibliográficas}

Agamben, G. (2007). Estado de excepción. Buenos Aires: Adriana Hidalgo.

Albornoz, M. (2017). Policías, cónsules y anarquistas: la dimensión transatlántica de la lucha contra el anarquismo en Buenos Aires (1889-1913). Iberoamericana, 17(64), 57-79.

Albornoz, M. y Galeano, D. (2017). Anarquistas y policías en el atlántico sudamericano: una red transnacional, 1890-1910. Boletin del Instituto de Historia Argentina y Americana "Dr. Emilio Ravignani”, 47, 101-134.

Anzoategui, I. y otros (1939). La ley $N^{\circ}$ 4144, de residencia. Buenos Aires: Facultad de Derecho, UBA.

Aspell, M. (1979). La Ley 4144 de residencia; antecedentes, sanción, aplicación. Revista del Instituto de Historia del derecho Ricardo Levene, 25, 11-127.

Barry, V. (2009). Orden en Buenos Aires. Policias y modernización policial, 1890- 1910 (Tesis de maestría inédita). Universidad Nacional de San Martín, San Martín, Argentina.

Belkin, A. (2015). La huelga general de enero de 1907 y las estrategias políticas de socialistas, anarquistas y sindicalistas revolucionarios. Estudios del trabajo, (49/50), 31-59. Recuperado de https://aset.org.ar/ojs/ revista/article/view/13/13

Caruso, L. (en prensa). "Las hazañas del trabajo": protesta y solidaridades en la huelga grande del Riachuelo, verano de 1904. En M. Lobato, M. (Comp.), Comunidades, historia locales y mundos del trabajo. Buenos Aires: Edhasa.

Domenech, E. (2015). Inmigración, anarquismo y deportación: la criminalización de los extranjeros indeseables en tiempos de las grandes migraciones. Revista Interdisciplinar da Mobilidade Humana, 23(45), 169-196. Recuperado de http://www.scielo.br/pdf/remhu/v23n45/1980-8585-REMHU-23-45-169. pdf

Dufey, E. (1913). La defensa social. Medios preventivos y represivos. Buenos Aires: Facultad de Derecho, UBA.

Franco, M. (2012a). Un enemigo para la nación. Buenos Aires: Fondo de Cultura Económica.

Franco, M. (2012b). Rompecabezas para armar: la seguridad interior como política de Estado en la historia argentina reciente (1958-1976). Revista Contemporánea, 3(3), 77-96. Recuperado de http://www.geipar. udelar.edu.uy/wp-content/uploads/2014/10/Contemporanea03_2012-11-23-webO-04.pdf

Franco, M. (2016). La represión estatal en la historia argentina reciente: problemas, hipótesis y algunas respuestas tentativas. En G. Águila, S. Garaño y P. Scatizza (eds), Violencias de Estado. Formas y dinámicas represivas en la historia reciente argentina: nuevos abordajes a 40 años del Golpe de Estado (pp. 15-43). La Plata: UNLP.

Frydenberg, J. y M. Rufo (1992). La semana Roja de 1909. Buenos Aires: CEAL. 
Giorliandini, E. (1986). Una historia negra: La Ley de residencia. Todo es historia, (226), 8-42.

Gonzalez Calleja, E. (2006). Sobre el concepto de represión. Hispania nova. Revista de Historia Contemporánea, (6). Recuperado de: http://hispanianova.rediris.es/6/dossier/6d022.pdf

Ingenieros, J. (1911). La defensa social. Buenos Aires: Talleres Gráficos de la Penitenciaría Nacional.

Larocca, P. (2008). La ley de residencia de 1902; el extranjero como enemigo. Revista de derecho penal y procesal penal, 12, 2061-2074.

Marengo Hecker, M.E. (2018). Los servicios de inteligencia de la Policía de la Provincia de Buenos Aires y la construcción del sujeto comunista (1955-1962). (Tesis de doctorado inédita). Universidad Nacional de La Plata, La Plata, Argentina.

Martínez Mazzola, R. (2003). ¿Cuestión social o cuestión nacional? Los debates en torno al naciente movimiento obrero. En S. Villavicencio (Ed.), Los contornos de la ciudadanía. Nacionales y extranjeros en la Argentina del Centenario, pp. 91-108. Buenos Aires: Eudeba.

Mc Gee Deutsch, S. (2003). Contrarrevolucion en Argentina, 1900-1932. La Liga Patriótica Argentina. Bernal: Universidad Nacional de Quilmes.

Nazar, M. (2008). El problema de la verdad histórica. Elementos para la configuración del concepto de trabajador construido desde el Estado durante el primer peronismo (1946-1955). (Tesis de licenciatura inédita). Universidad de Buenos Aires, Buneos Aires, Argentina.

Oved, I. (1976). El trasfondo histórico de la ley 4144 de residencia. Desarrollo Económico, 61(16), 123-150.

Pacecca, M.I. (2003). El fantasma en la máquina: la praxis política de los extranjeros y la Ley de Residencia. En S. Villavicencio (Ed.). Los contornos de la ciudadanía. Nacionales y extranjeros en la Argentina del Centenario. Buenos Aires: Eudeba.

Pavón, C. (1913). La defensa social. Medios preventivos y represivos. Buenos Aires, Aveledo.

Pèries, G. (2013). La subversion prise par le bout des doigts, Politix, 104(4), 113-153. Recuperado de https://www.cairn.info/revue-politix-2013-4-page-133.htm\#

Pontoriero, E. (2017). La seguridad interna como "teatro de guerra": estado de excepción y contrainsurgencia en Argentina (1955-1976). (Tesis de doctorado inédita). Universidad Nacional de San Martín.

Rojkind, I. (2006). Prensa, manifestaciones y oposición política. La protesta contra la unificación de la deuda en julio de 1901, Estudios Sociales, 31(1), 137-162.

Sánchez Viamonte, C. (1956). Biografia de una ley antiargentina, Buenos Aires, NEAR.

Scarzanella, E. (2015). Ni gringos ni indios. Inmigración, criminalidad y racismo en la Argentina, 1980-1940. Buenos Aires: Universidad Nacional de Quilmes. 
Schmitt, C. (1985). La dictadura: desde los comienzos del pensamiento moderno de la soberanía hasta la lucha de clases proletaria. Madrid: Alianza [1921].

Suriano, J. (1983). La buelga de inquilinos de 1907. Buenos Aires: CEAL.

Suriano, J. (1989-1990). El Estado argentino frente a los trabajadores urbanos: política social y represión, Anuariode la Escuela Historia-Universidad nacional de Rosairo, (14), 101-136.

Suriano, J. (Comp.) (2000). La cuestión social en Argentina. 1870-1943. Buenos Aires: La Colmena.

Suriano, J. (2001). Anarquistas, Cultura y politica libertaria en Buenos Aires, 1890-1910. Buenos Aires: Manantial.

Taussig, M. (1995). Un gigante en convulsiones. Barcelona: Gedisa.

Zimmermann, E. (1995). Los liberales reformistas. La cuestión social en la Argentina 1890- 1916. Buenos Aires: Sudamericana/Universidad de San Andrés.

Ziulu, G. (2000). Estado de sitio, ̨̇emergencia necesaria o autoritarismo encubierto?. Buenos Aires: Depalma. 